\title{
Article \\ Effectiveness of Hyaluronan Autocross-Linked-Based Gel in the Prevention of Peritendinous Adherence Following Tenolysis
}

\author{
Andrea Marchesini ${ }^{1,+}{ }^{\dagger}$, Francesco De Francesco ${ }^{1, *,+}+\mathbb{D}$, Pier Paolo Pangrazi ${ }^{1}$, Letizia Senesi ${ }^{1}{ }^{(0)}$, \\ Andrea Campodonico ${ }^{1}$, Valentina Riccio ${ }^{2}$, Stefano Geuna ${ }^{3}{ }^{-}$, Barbara Zavan ${ }^{4}$ and Michele Riccio ${ }^{1}$ \\ 1 Department of Plastic and Reconstructive Surgery-Hand Surgery Unit, Azienda 'Ospedali Riuniti' \\ 60126 Ancona, Italy; andrea.marchesini@ospedaliriuniti.marche.it (A.M.); \\ pierpaolo.pangrazi@ospedaliriuniti.marche.it (P.P.P.); letizia.senesi@gmail.com (L.S.); \\ andrea.campodonico@ospedaliriuniti.marche.it (A.C.); michele.riccio@ospedaliriuniti.marche.it (M.R.) \\ 2 Veterinary Medical School, University of Camerino, 62024 Camerino, Italy; valyriccio91@gmail.com \\ 3 Department of Clinical and Biological Sciences \& Neuroscience Institute of the Cavalieri Ottolenghi \\ Foundation, University of Turin, 10124 Turin, Italy; stefano.geuna@unito.it \\ 4 Department of Morphology, Surgery and Experimental Medicine, University of Ferrara, 44121 Ferrara, Italy; \\ zvnbbr@unife.it \\ * Correspondence: francesco.defrancesco@ospedaliriuniti.marche.it; Tel.: +39-071-5963945; \\ Fax: +39-071-5965297 \\ + The authors contributed equally to the work.
}

check for updates

Citation: Marchesini, A.; De Francesco, F.; Pangrazi, P.P.; Senesi, L.; Campodonico, A.; Riccio, V.; Geuna, S.; Zavan, B.; Riccio, M. Effectiveness of Hyaluronan Autocross-Linked -Based Gel in the Prevention of Peritendinous Adherence Following Tenolysis. Appl. Sci. 2021, 11, 7613. https://doi.org/10.3390/app11167613

Academic Editor: Wei Long Ng

Received: 27 July 2021

Accepted: 17 August 2021

Published: 19 August 2021

Publisher's Note: MDPI stays neutra with regard to jurisdictional claims in published maps and institutional affiliations.

Copyright: (C) 2021 by the authors Licensee MDPI, Basel, Switzerland. This article is an open access article distributed under the terms and conditions of the Creative Commons Attribution (CC BY) license (https:/ / creativecommons.org/licenses/by/ $4.0 /)$.
Featured Application: Local application of Hyaloglide ${ }^{\circledR a v o i d s ~ a d h e r e n c e ~ f o r m a t i o n ~ a f t e r ~ t e n o l-~}$ ysis and supports normal restoring with regeneration of the synovial sheath in a rabbit model.

Abstract: Peritendinous adhesions are a frequent occurrence following tenolysis and present a major clinical challenge regarding prevention and management, with no recovery assured from conservative or surgical approaches. Herein, we investigated the effectiveness of Hyaloglide ${ }^{\circledR}$, a hyaluronan gel-based product with a novel autocross-linked technology, in a rabbit model affected by tenolysis on the flexor digitorum communis tendon (FDC). A 1.5-cm-long scrubbing of the tendon surface was performed bilaterally to induce peritendinous adhesion on FDC of 30 animals with subsequent application of Hyaloglide ${ }^{\circledR}$ on the surrounding injured area, in one randomly chosen tendon. The contralateral tendon was treated with saline solution as the control. We sacrificed the rabbit models after 45 days of surgery and quantitatively assessed the generation of peritendinous adherence and regeneration of the tendon sheaths using histological (hematossyline-eosine, masson's trichromic), histomorphometrical (Tang score, Soslowsky Svesson, and Cook score), light electron microscopic, and gene expression investigations. Four rabbits were devoted to biomechanical analysis. Peritendinous adhesions were limited in Hyaloglide ${ }^{\circledR}$-treated tendons; moreover, well-regenerated tendon sheaths were observed conversely to untreated tendons presenting with extensive areas of adhesions on the tendon surface. Histomorphometrical analysis revealed an adhesion score (Tang score) significantly better in the treated group $(p=0.001 *)$ compared to the control group. Moreover, the Soslowsky, Svensson, and Cook score parameters revealed a significantly improved regeneration for fiber structure, cellularity, and vascularity in the treated group $\left(p=0.001{ }^{*}\right)$. No differences were reported for cartilaginous formation $(p=0.08)$. Gene expression analysis showed a significant increase in collagen type I expression in the treated group compared to the control group, while metalloprotease 1 and 9 were significantly increased in the control group. Biomechanical analysis did not show significant differences in both groups. Hyaloglide ${ }^{\circledR}$ treatment was safe and welltolerated, generating improved tissue status. Local application of Hyaloglide ${ }^{\circledR}$ prevents adhesion formation after tenolysis and promotes normal healing with regeneration of the synovial sheath in a rabbit model. 
Keywords: tendon injuries; tenolysis; histology; animal model; hyaluronan gel; autocross-linked gel; peritendinous adhesions

\section{Introduction}

Tendons are a histologic high-tensile-strength band of dense fibrous connective tissue that connects muscles and bones and enable joint movement [1] by transmitting the force developed in the muscle to the bone. Tendons are equipped with a coverage, so-called peritendinous synovial sheaths [2], which facilitate their movement and protect them from the friction of surrounding tissue and organs. Two fibrous sheaths (parietal and visceral) that constitute a closed tube with peritendinous fluid for lubrification are located under a fibrous layer and some tendons possess a peritendinous fibrillar sheath of elastic tissue enabling the tendons to move freely in relation to the surrounding tissues.

Adhesion formation following tendon repair and/or tenolysis in the area between the tendon and the surrounding tissue is a critical issue for the surgeon [3-5]. Tendon injury will initially provide an inflammatory response, but developing adhesions and scar tissue will subsequently inhibit the gliding movement of the tendon [6,7]. The prevention of peritendinous adhesions post tenolysis has been investigated using numerous techniques, with an objective to separate the recovering tendon from the surrounding wound area with an intent to decrease inflammation and subsequent scar tissue formation around the surface of the tendon, thus reducing the formation of adhesions. An optimal material, therefore, should neither inhibit the synovial sheath of the tendon to naturally regenerate nor should it interfere with its repair mechanism [8].

Authors have proposed various techniques, such as tissue engineering, which permits the withdrawal of biological membranes from other tissues or the application of synthetic membrane to encase the lesion area and enable the generation of a peritendinous barrier. Strauch and co-authors [9] used autologous vein grafts during primary tendon repair and obtained favorable outcomes in functionality compared to controls. Furthermore, the enveloping role of the amniotic membrane in chickens prevented peritendinous adhesions following tendon repair [10]. Biological membranes derived from the peritoneum [11], pericardium [12], fascial grafts, and fascial flaps [13,14] have also been investigated. Studies have also revealed the efficacy of fibrin sealant applied to the lesion, reducing post-surgical tendon adhesion formation $[15,16]$.

Beneficial effects have been observed concerning autogenous transplantation of biological tissues from diverse sources. This cost-effective and accessible technique allows for a barrier to be formed, which is similar to a normal tendon sheath. Polytetrafluoroethylene, millipore cellulose tubes, and silastic, hydroxyapatite or alumina [17], and polyethylene membranes [18] are among the alternative mechanical barriers successfully employed to prevent tendon adhesion following surgery.

Hyaluronic acid or its derivatives regarding injured tendons have recently been discussed and examined, revealing a reduction in post-surgical peritendinous adhesions in repaired tendons on administration of hyaluronic acid [19-24]. It is also noteworthy that human amniotic fluid (HAF) possesses a high molecular weight with elevated concentrations of hyaluronic acid and acts as a hyaluronic acid-stimulating activator, which may be used alone or with hyaluronic acid to prevent peritendinous adhesions $[25,26]$.

Recent investigations have revealed positive outcomes in the local administration of autocross-linked derivatives with hyaluronic acid, specifically ACP, displaying safety and biocompatibility properties and reduced post-surgery adhesion in various sites. De Iaco [27] and Belluco [28] demonstrated the clinical use and efficacy of ACP in preventing adhesion following abdominal surgery. Moreover, other authors reported ACP efficacy following knee surgery in a preclinical setting [29] and in nerve reconstruction in both preclinical and clinical contexts [30]. Riccio and colleagues showed that ACP is effective in the treatment of pathological scars [31]. 
A biomaterial barrier that blocks the infiltration of cells but enables the passage of cytokines and GFs may be useful to avoid adhesion formation, without altering the normal healing process.

Recently, Imere et al. [32] developed a bilayer membrane combining a nanofibrous poly ( $\varepsilon$-caprolactone) (PCL) electrospun mesh with a layer of self-assembling peptide hydrogel (SAPH) laden with type-B synoviocytes that showed good biomechanical behavior, preventing post-operative tendon adhesion. Chen et al. [33] also developed a multifunctional nano fibro membrane that acts as a physical barrier to prevent fibroblast penetration. Hyaluronic acid reduced fibroblast attachment and helped lubrification and tendon gliding, with ibuprofene adjunct acting as an anti-inflammatory drug.

Moreover, Yurdakul et al. [34] recently compared a bioresorbable membrane composed of sodium hyaluronate and carboxymethyl cellulose and an auto-crossed linked gel derivative from hyaluronic acid in preventing tendon adhesion after crush injuries, showing that the gel was effective only after tendon fiber repair in a rat model.

A multicenter clinical trial recently investigated an autocross linked hyaluronan-based gel (Hyaloglide ${ }^{\circledR}$ ), revealing positive results in preventing adhesion recurrence following tenolysis of flexor tendons in zone II of the hand [3]. This non-stick mechanism, albeit clinically effective, has been scarcely examined in animal models. In this context, we herein assess, for the first time, the effectiveness of Hyaloglide ${ }^{\circledR}$, a resorbable gelformulated adhesion barrier, on rabbit models affected by tenloysis, showing positive results in the prevention of peritendinous adhesions. The study particularly concentrated on the histological and electron microscopy analyses. Owing to its mechanical characteristics, Hyaloglide ${ }^{\circledR}$ may enhance regeneration of the tendon synovial sheath, ensuring tendon elasticity and avoiding peritendinous adhesion formation, thus enabling favorable recovery of tendon function.

The aim of the present study was to assess the efficacy of Hyaloglide ${ }^{\circledR}$ application in tendon adhesion prevention through the evaluation of primary endpoints, such as the histological and histomorphometrical score, and secondary endpoints, such as gene expression analysis and biomechanical evaluation.

We hypothesized that in the treated group, the evaluated scores would be statistically better compared to the control group.

\section{Materials and Methods}

\subsection{In Vivo Study Design}

Thirty adult male New Zealand rabbits weighing 2 to $3 \mathrm{~kg}$ were selected for tendon analysis. At the end of the study, all animals underwent macroscopic evaluation (histological and histomorphometrical evaluation), then four rabbits were randomly assigned to biomechanical analysis. The remaining 26 animals underwent light electron microscopy and gene expression evaluation.

The protocol was approved by the Italian Ministry of Health (authorization number CP 1-10/09). The animals were treated according to the institutional and national guidelines for the care and use of laboratory animals and approved by the local Institution's Animal Care and Ethics Committee, conforming to the European Communities Council Directive of 22 September 2010 (2010/63/UE).

The rabbit tendon is larger and similar to the human model and is considered an appropriate experimental model. The tendon of the FDC muscle of the posterior limb is a long tendon with a distinct peritendinous sheath and is surgically attainable and consistent with our type of investigation [35].

Furthermore, a type of lesion that emulates tenolysis in a clinical context was required, therefore we scrubbed the tendon surface $(1.5 \mathrm{~cm}$ in length) from the proximal and distal, performing a slit proportional to $40 \%$ of the tendon caliber.

Herein, we investigated the efficacy of Hyaloglide ${ }^{\circledR}$ or auto-cross-linked polysaccharide ACP gel (Fidia Advanced Biopolymers, Abano Terme, Italy) in preventing post-surgical peritendinous adhesions. Moreover, peritendinous frictions during physical activity will be 
reduced, resulting in improved regeneration of the tendon sheaths. We conducted a threephase analysis: (1) assessment of the gliding function of the tendon was performed via macroscopic examination at the time of tendon explant; (2) light electron microscopy was used to evaluate adhesion and the peritendinous tendon sheaths; and (3) biomechanical evaluation of the tendon was assessed by taking four samples from each group.

The rate of adhesion formation and regeneration of the synovial sheaths was evaluated in the animal models using a 4-point semi-quantitative grading system and macroscopic, microscopic, and ultrastructural investigations. Two independent masked observers assessed the sample results, presenting the mean score as the mean between two scores. The score of the adhesion formation was evaluated as follows: 0 — severe adherence; 1 -moderate adherence; 2 -few adherences; 3 -no adherence. The synovial sheath regeneration was scored as follows: 0 -very poor regeneration; 1 -poor regeneration; 2 -moderate regeneration; 3-successful regeneration.

\subsection{Surgical Procedure}

The animals enrolled in the study were kept in large cages in a room under controlled temperature and humidity conditions with $12-12 \mathrm{~h}$ light/dark cycles.

The rabbits were intravenously anesthetized with $0.1 \mathrm{~mL}$ of Zoletil $100,0.5 \mathrm{~mL}$ of Rompum, $3.5 \mathrm{~mL}$ of saline solution, $30 \mathrm{mg} / 1 \mathrm{~kg}$ body weight, and the tendon of the FDC proximal to the ankle was exposed.

The animals were positioned face down and surgery was performed under sterile manners. The skin from the dorsal side of the left thigh was trimmed and cleansed using antiseptic solution according to normal practice.

We surgically impaired the tendon sheath of 30 rabbits, precisely a bilateral $1.5-\mathrm{cm}$ long segment of the tendon sheath around the circumference to emulate tenolysis, which commonly arises in patients (Figure 1). We performed an incision at the center of the injured tendon segment equivalent to $40 \%$ of the tendon diameter, bilaterally. This procedure permitted the precise identification of the lesion site at withdrawal. We randomly selected one tendon in each animal and applied $1 \mathrm{~mL}$ of Hyaloglide ${ }^{\circledR}$ around the injured tendon segment. We administered $1 \mathrm{~mL}$ of saline solution to the contra-lateral segment applying the solution around the tendon in accordance with the treated tendon. We proceeded to suture the skin of both the posterior's paws with $4 / 0$ reasorbable sutures.
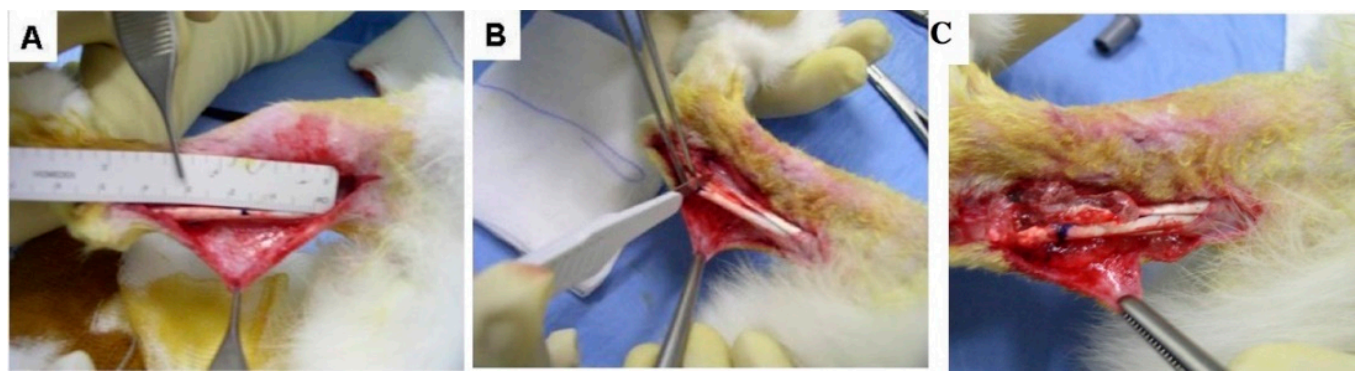

Figure 1. Surgical steps. (A) Approach to the tendon. (B) Tendon damage is performed. (C) Hyaloglide ${ }^{\circledR}$ application to the tendon injury site.

The rabbits were housed in single crates post-surgery for three days and a dosage of 300,000 units of intramuscular penicillin intramuscular was administered during the first three postoperative days to prevent infections. We did not immobilize the hind limbs.

Therefore, animals were conceded normal cage activities under standard laboratory conditions and sustained with standard chow and water ad libitum.

After 45 days, animals were then sacrificed using a $300 \mathrm{mg} / \mathrm{kg}$ pentobarbital overdose.

\subsection{In Vitro Study Design}

The damaged tendons were then accessed, and macroscopic investigation performed to monitor gliding movements and the formation of peritendinous adhesions. 
Macroscopic scoring of adhesions was conducted prior to tendon withdrawal in all 30 animals, while biomechanical tests of resistance were carried out on 4 samples from each randomly chosen group. The remaining tendons were separated into two 1-cm-long samples, one sample proximal to the tenotomy and the other sample distal to the tenotomy. The samples were then subjected to light and electron microscopy and gene expression analysis and respectively analyzed.

\subsection{Histology}

The samples were prepared for light microscopy by fixing the tendons in $10 \%$ formalin for $12 \mathrm{~h}$ then were dehydrated in alcohol, clarified in xylene, and embedded in paraffin. The samples were cut at 6-8 $\mu \mathrm{m}$ perpendicular to the tendon axis and the sections (6-10 micron) were stained with hematoxylin-eosin (HE) and Masson's trichromic stain and observed with a DM400 microscope equipped with a DFC320 digital camera and IM1000 image manager system (Leica Microsystems, Wetzlar, Germany).

\subsection{Histomorphometry}

Histological images of the stained H\&E and Masson's trichrome sections were taken for digital analysis at a 10X and 20X magnification. Two masked histologists scored the images using two semiquantitative scores: The Tang score (Table 1) [36] to assess the total adhesions, and the Soslowsky, Svesson, and Cook score (Table 1) [37-39] was adopted to analyze tendon regeneration. The collagen fibril orientation was analyzed by the fast Fourier transform (FTT) method (ImageJ 1.53a, NIH) and by a semi-quantitative method. These methods were previously validated by the same authors [40].

Table 1. The Tang score, used to evaluate adhesion of tendons, and Soslowsky, Svesson, and Cook (SSV) score, used to evaluate tendon regeneration.

\begin{tabular}{|c|c|c|c|c|}
\hline Score & \multicolumn{2}{|c|}{ Quantity } & \multicolumn{2}{|c|}{ Quality } \\
\hline 0 & \multicolumn{2}{|c|}{ No adhesion } & \multicolumn{2}{|c|}{ No adhesion } \\
\hline 1 & \multicolumn{2}{|c|}{ Sparse filaments } & \multicolumn{2}{|c|}{ Regular, elongated and thin filaments } \\
\hline 2 & \multicolumn{2}{|c|}{ High number of filaments } & \multicolumn{2}{|c|}{ Irregular and short filaments } \\
\hline 3 & \multicolumn{2}{|c|}{ Countless strands } & \multicolumn{2}{|c|}{ Dense and non-filamentous adhesions } \\
\hline & \multicolumn{4}{|c|}{ DEGREE of ADHESION (sum of previous score) } \\
\hline 0 & \multicolumn{4}{|c|}{ No adhesion } \\
\hline 2 & \multicolumn{4}{|c|}{ Slight adhesion } \\
\hline $3-4$ & \multirow{2}{*}{\multicolumn{4}{|c|}{ Moderate adhesion }} \\
\hline $5-6$ & & & & \\
\hline SSV Score & 0 & 1 & 2 & 3 \\
\hline FIBER STRUCTURE & $\begin{array}{l}\text { Normal structure with } \\
\text { parallel and compact } \\
\text { collagen fibers }\end{array}$ & $\begin{array}{l}\text { Slight changes with } \\
\text { separate collagen } \\
\text { fiberswith increased } \\
\text { ripple }(<25 \%)\end{array}$ & $\begin{array}{l}\text { Moderate changes with } \\
\text { disorganized, separate } \\
\text { and disoriented } \\
\text { collagen fibers }(\geq 25 \% \\
\text { and } \leq 50 \%)\end{array}$ & $\begin{array}{l}\text { Marked changes with } \\
\text { disorganized and } \\
\text { hyalinized collagen } \\
\text { fibers }(>50 \%)\end{array}$ \\
\hline $\begin{array}{l}\text { CELLULARITY } \\
\text { (ASPECT) }\end{array}$ & $\begin{array}{l}\text { Tapered and elongated } \\
\text { nuclei, not very visible } \\
\text { and with } \\
\text { little cytoplasm }\end{array}$ & $\begin{array}{l}\text { Increased cell rotondity: } \\
\text { nuclei become less oval } \\
\text { and rounder with } \\
\text { little cytoplasm }\end{array}$ & $\begin{array}{l}\text { Increased roundness } \\
\text { and cellular size: the } \\
\text { nuclei become round } \\
\text { with an increase in } \\
\text { the cytoplasm }\end{array}$ & $\begin{array}{l}\text { The nucleus appears } \\
\text { round and wide with } \\
\text { abundant cytoplasm } \\
\text { and lacuna formation }\end{array}$ \\
\hline VASCULARITY & $\begin{array}{l}\text { The few vessels are } \\
\text { parallel to the } \\
\text { collagen fibers }\end{array}$ & $\begin{array}{l}\text { Slight increase in } \\
\text { the vessels }\end{array}$ & $\begin{array}{l}\text { Moderate increase in } \\
\text { the vessels }\end{array}$ & $\begin{array}{l}\text { Marked increase in } \\
\text { the vessels }\end{array}$ \\
\hline $\begin{array}{l}\text { CARTILAGINEOUS } \\
\text { FORMATION }\end{array}$ & $\begin{array}{l}\text { No cartilaginous } \\
\text { formation }\end{array}$ & $\begin{array}{l}\text { Isolated hyaline } \\
\text { cartilage nodules }\end{array}$ & $\begin{array}{l}\text { Moderate cartilaginous } \\
\text { formations }(25-50 \%)\end{array}$ & $\begin{array}{l}\text { Extended cartilaginous } \\
\text { formations }(>50 \%)\end{array}$ \\
\hline
\end{tabular}




\subsection{Electron Microscopy}

Tendon samples were fixed in $2.5 \%$ glutaraldehyde (Fluka, St. Louis, MO, USA) and $0.5 \%$ saccharose in $0.1 \mathrm{M}$ Sörensen phosphate buffer for 6-8 $\mathrm{h}$. The samples were then rinsed in $1.5 \%$ saccharose in $0.1 \mathrm{M}$ Sörensen phosphate buffer for 6-12 h, post-fixed in $2 \%$ osmium tetroxide, dehydrated, and placed in Glauert's embedding mixture 34 containing equal parts of Araldite M and Araldite Härter, HY 964 (Merck, Darmstadt, Germany) and an additional 2\% of DY 064 accelerator (Merck, Darmstadt, Germany). The plasticizer dibutyl phthalate was added at $0.5 \%$.

Semi-thin sections $(1 \mu \mathrm{m})$ were obtained, then ultra-thin sections were cut $(70-100 \mathrm{~nm})$ using a Leica Ultracut UCT. The semi-thin sections were stained with toluidine blue for 2-3 min and observed under a DM400 microscope equipped with a DFC320 digital camera and an IM1000 image manager system (Leica Microsystems, Wetzlar, Germany). The ultrathin sections were stained with uranyl acetate and lead citrate and then analyzed under a JEM-1010 transmission electron microscope (JEOL, Tokyo, Japan).

\subsection{Gene Expression}

Complementary DNA (cDNA) was made from 200 ng of total RNA using M-MLV Reverse Transcriptase (Invitrogen, Carlsbad, CA, USA) or a miRcute miRNA First-strand cDNA Synthesis Kit (Tiangen Biotech, Shangai, China), following the manufacturer's protocols. Real-time PCRs were performed with a Rotor-Gene 3000 (Corbett Research, Sydney, Australia) using the $300 \mathrm{nM}$ concentration of the designed primers and FastStart SYBR Green Master (Roche Diagnostics, Mannheim, Germany). Differences in gene expression were evaluated by the 2delta $\mathrm{Ct}$ method. Values were normalized to the expression of the glyceraldehyde-3-hosphate dehydrogenase (GAPDH) housekeeping gene. The mature miRNAs expression levels in tendons treated and not treated were estimated with the miRcute miRNA qPCR detection kit (Qiangen).

\subsection{Biomechanical Analysis}

The specimens were mounted onto a Bionix 100 mechanical testing system (MTS System Limited, Cirencester, UK). A preload force of $2 \mathrm{~N}$ was applied as the initial tension. The tendons were marked with black ink $\sim 5 \mathrm{~mm}$ away from the site of laceration. The tendons were then loaded to failure at a constant speed of $20 \mathrm{~mm} / \mathrm{min}$. The collected data were used to calculate the biomechanical properties of each specimen.

\subsection{Statistical Analysis}

The sample size was calculated a priori using the paired t-test, with at least $80 \%$ power and an alpha-error of 0.05 obtained from a previous study comparing the Soslowsky, Svensson, and Cook score in the treated and control tendons [41]. Power and sample size were analyzed using G-Power software version 3.1.9.2.

Data of the adhesion formation and the synovial sheath regeneration and biomechanical analysis were not normally distributed. Accordingly, all statistical analyses were performed via a nonparametric approach: the Wilcoxon test was adopted to compare the te groups. Statistical significance was set as $p<0.05$. The mean values for quantitative data were compared, applying the Anova test for RT-PCR results. Statistical significance was set as $p<0.05$.

\section{Results}

\subsection{General Conditions and Macroscopic Evaluations}

Anesthesia, surgery, and Hyaloglide ${ }^{\circledR}$ application were well tolerated in the animals with no presentation of necrosis or infections. At the follow-up examinations, no adverse events were reported following administration of Hyaloglide ${ }^{\circledR}$. Macroscopic qualitative analysis of the injured tendons revealed fewer peritendinous adhesions in the tenolysis site of the Hyaloglide ${ }^{\circledR}$-treated tendons (Figure 2A,C) compared to the untreated control group (Figure 2B,D). 

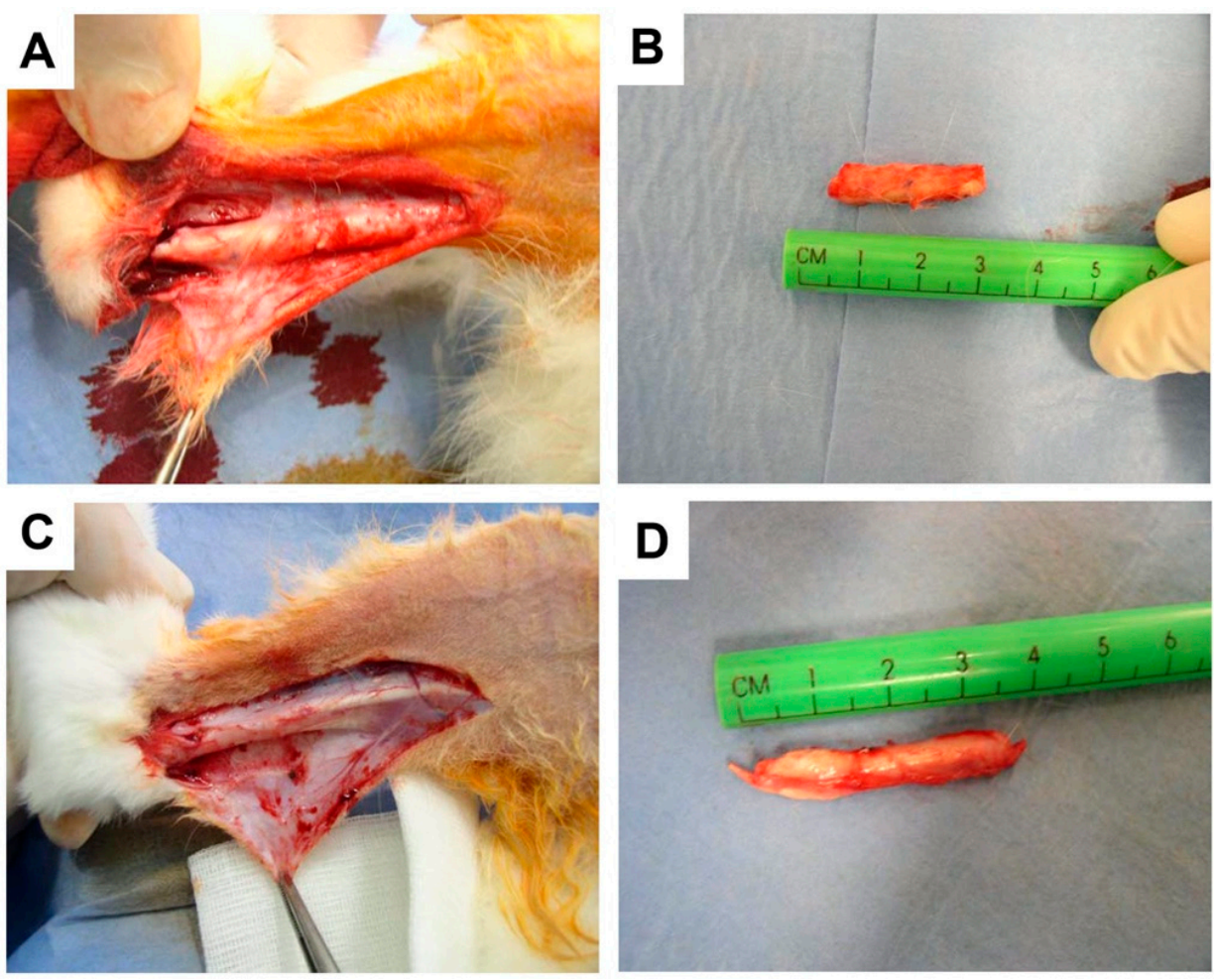

Figure 2. Macroscopic analysis of tendon adherences at time of explant. (A,B) Hyaloglide ${ }^{\circledR}$ group. (C,D) Control unprotected group.

The adhesion rates and grades of the groups are presented in Table 2. In comparing adhesion grades, a significant difference was found between the control group and the treatment group $(p<0.001)$.

Table 2. Post-operative adhesion rates and grades for two groups.

\begin{tabular}{|c|c|c|c|c|c|c|c|}
\hline \multicolumn{8}{|c|}{ Adhesion Grade } \\
\hline Group & $\mathbf{N}^{\circ}$ Rabbit & 0 & 1 & 2 & 3 & 4 & Adhesion Rate (\%) \\
\hline Hyaloglide & 30 & 26 & 4 & 0 & 0 & 0 & $4 / 30(10)$ \\
\hline Non-Treated & 30 & 0 & 0 & 1 & 4 & 25 & $30 / 30(100)$ \\
\hline
\end{tabular}

\subsection{Histological Evaluations}

The peritendinous sheaths in the Hyaloglide ${ }^{\circledR}$-treated tendons were similar in appearance to normal tendons (data not shown), while in the untreated tendons, we observed denser surroundings, disorganized, deteriorated, and separated collagen fibers and extensive adhesion sites. We reported fewer peritendinous adhesions in the Hyaloglide ${ }^{\circledR}$-treated samples and clearly noted well-regenerated synovial sheaths, including parallel collagen fibers and an organized architecture, devoid of an overlapping fibrous architecture. Moreover, we observed extended cells with a less pronounced cytoplasm with no inflammatory infiltration (Figure 3A-E). Hypercellularity zones with round cells and large adhesion sites in proximity to the tendon surface were evident in the untreated tendons (Figure 3F-H). 

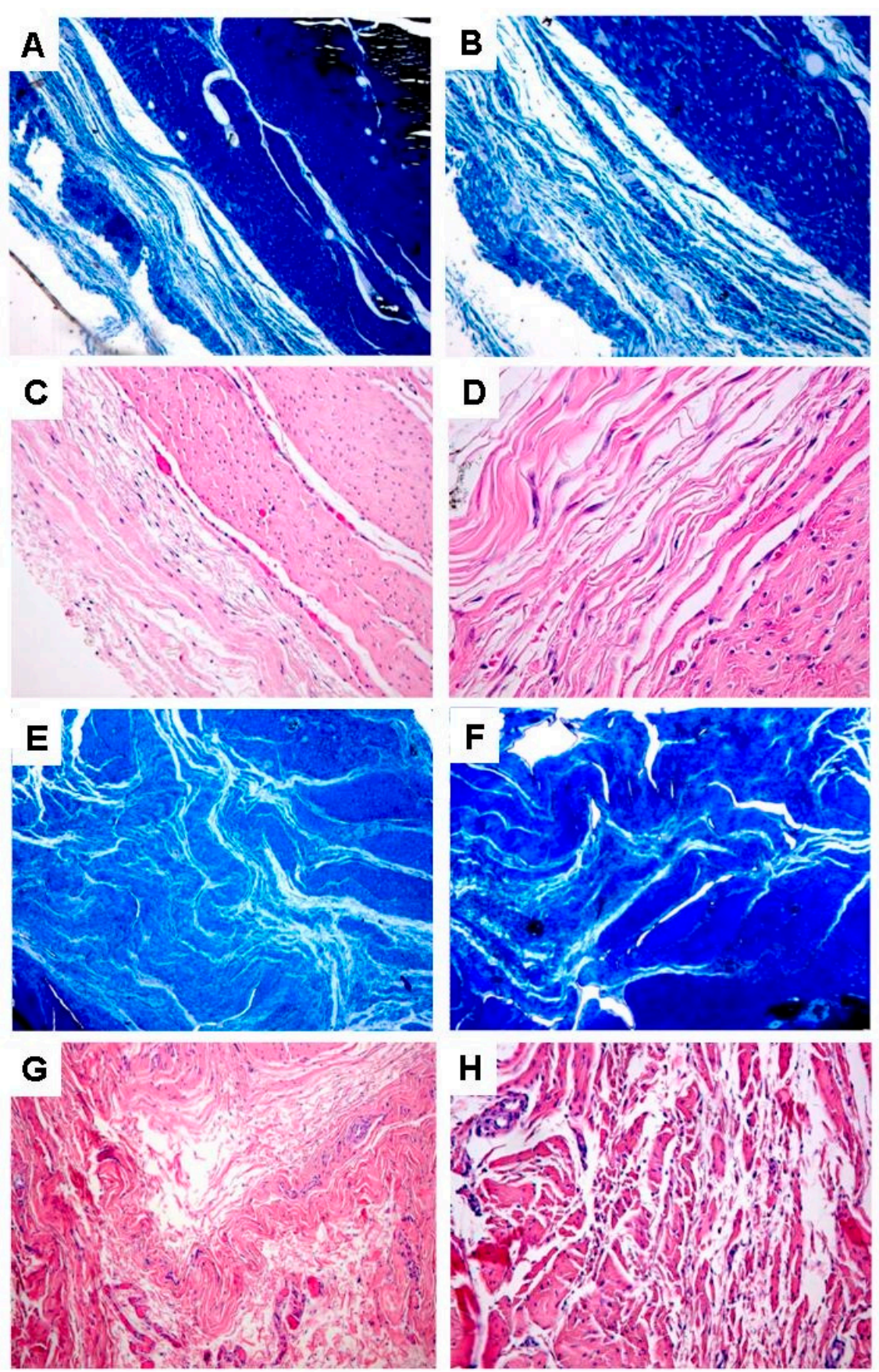

Figure 3. High magnification light microscopy analysis following Masson's Trichrome (A,B,E,F) and Hematoxylin and Eosin $(\mathbf{C}, \mathbf{D}, \mathbf{G}, \mathbf{H})$ staining. (A-D) Hyaloglide ${ }^{\circledR}$ group. (E-F) Control untreated group. Magnification: $(\mathbf{A}, \mathbf{C}, \mathbf{E}, \mathbf{G})=400 X ;(B, D, F, H)=900 X$.

\subsection{Histomorphometric Evaluations}

We also observed relevant improvements in the tendons treated with Hyaloglide ${ }^{\circledR}$ compared to the untreated tendon. The positive outcomes were highlighted via comparative statistical analysis of the adhesion evaluation score (Tang score) and tendon regeneration (Soslowsky, Svensson, and Cook score) specifically reporting decreased adhesion formation: (Tang score: total adhesions $\mathrm{OR}=0.01, p=0.001 *$ ) (Figure 4A, Table 3). An improved regeneration was also evident (Soslowsky, Svensson, and Cook score: fiber structure $\mathrm{OR}=0.08, p=0.001$ *; cellularity $\mathrm{OR}=0.03, p=0.001$; vascularity $\mathrm{OR}=0.03$, $p=0.001 *$. No statistical differences were reported for cartilaginous formation $\mathrm{OR}=0.10$, $p=0.08$ ); (Figure 4B-E, Table 3). 


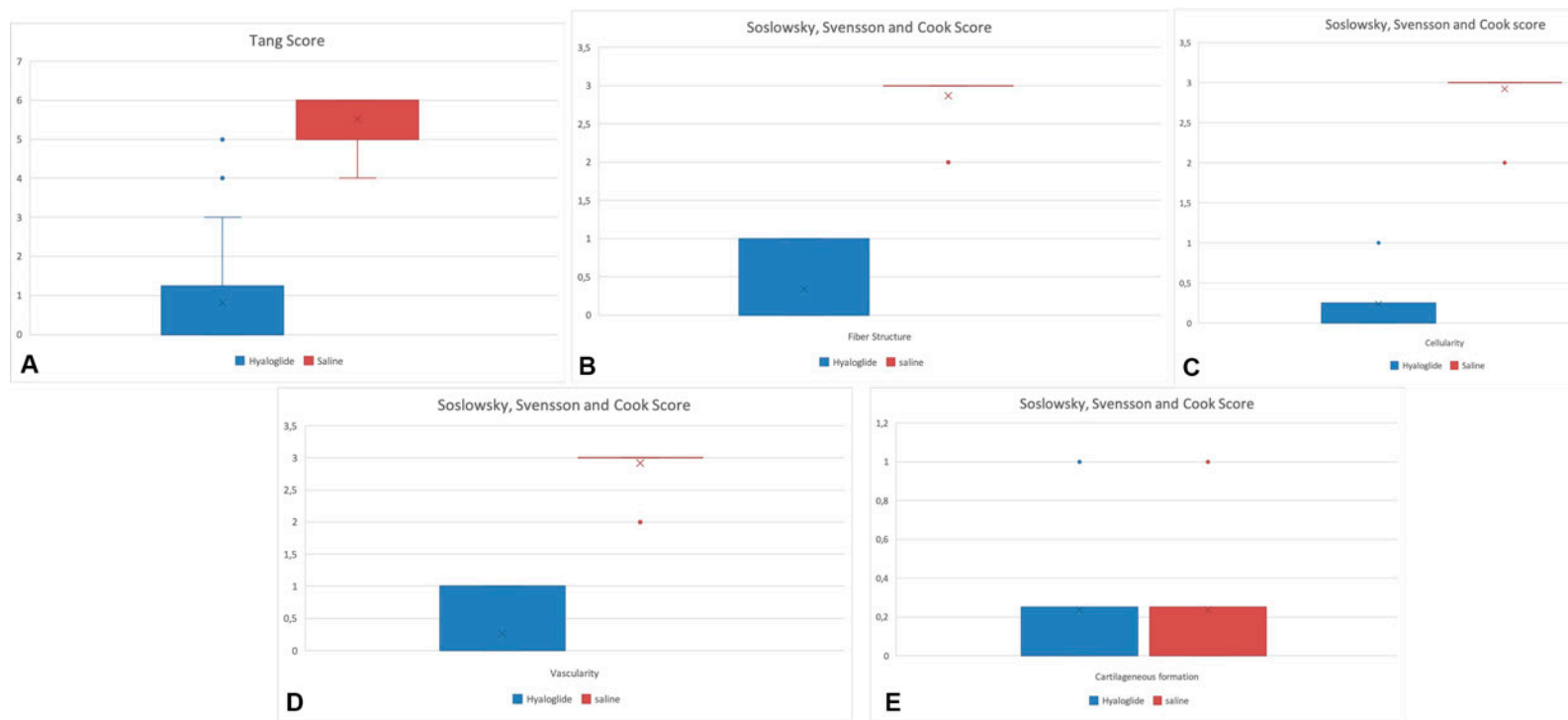

Figure 4. The positive outcomes of the Hyaloglide group were highlighted via comparative statistical analysis of the adhesion evaluation score (Tang score: total adhesions $\mathrm{OR}=0.01, p<0.05)(\mathbf{A})$ and tendon regeneration (Soslowsky, Svensson, and Cook score: fiber structure $\mathrm{OR}=0.08, p<0.05$ (B); cellularity $\mathrm{OR}=0.03, p<0.05$ (C); vascularity $\mathrm{OR}=0.03$, $p<0.05$ (D); cartilaginous formation $\mathrm{OR}=0.10, p>0.05(\mathbf{E})$ ) specifically reporting decreased adhesion formation and an improved regeneration.

Table 3. Tang score and Soslowsky, Svesson, and Cook score results of tendons treated or not with Hyaloglide.

\begin{tabular}{lcc}
\hline \multicolumn{1}{c}{ PARAMETER } & CONTROL & HYALOGLIDE \\
\hline TANG SCORE & $5.52 \pm 0.7$ & $0.81 \pm 1.4$ \\
SOSLOWSKY, SVESSON, & $2.9 \pm 0.34$ & $0.34 \pm 0.5$ \\
COOK & & \\
(FIBER STRUCTURE) & & $0.23 \pm 0.43$ \\
$\begin{array}{l}\text { SOSLOWSKY, SVESSON, } \\
\text { (CELLULARITY) }\end{array}$ & $2.92 \pm 0.3$ & \\
SOSLOWSKY, SVESSON, & & $0.26 \pm 0.44$ \\
$\begin{array}{l}\text { COOK } \\
\text { (VASCULARITY) }\end{array}$ & $2.92 \pm 0.3$ & \\
$\begin{array}{l}\text { SOSLOWSKY, SVESSON, } \\
\text { COOK } \\
\text { (CARTILAGINEOUS }\end{array}$ & & $0.24 \pm 0.43$ \\
FORMATION) & $0.24 \pm 0.43$ & \\
\hline
\end{tabular}

The results on collagen orientation show similar results to the Fourier analysis and semiquantitative evaluation, using a scale from 0 (extremely parallel) to 1 (extremely random), as suggested by Van Zuijlen and colleagues [40]. The collagen orientation index is the ratio of the minor axis and the major axis of the thresholder Fourier power plot. An example of collagen bundle orientation measurement by Fourier analysis is provided in Figure 5.

\subsection{Electron Microscope Evaluations}

Electron microscope analysis of the synovial sheaths (Figure 6) revealed that the synovial sheaths were arranged in stratified layers with large cleavage spaces (Figure 6A) in the tendons treated with Hyaloglide ${ }^{\circledR}$, with a similar arrangement observed in normal tendon sheaths (Figure 6B). We also noted an increased packed density of the collagen fibers related to the normal tendons, albeit organized in parallel fascicles (Figure 6C) with typical differences in dimension between the inner visceral layer (Figure 6D) and the external 
fibrous layer (Figure 6E). Contrastingly, neither the cleavage spaces nor stratification of the peritendinous sheaths were well delineated in the untreated tendons (Figure 6E,F). However, substantial collagen fiber bundles of various sizes were present in a densely packed assembly and with no distinct orientation (Figure 6G,H).

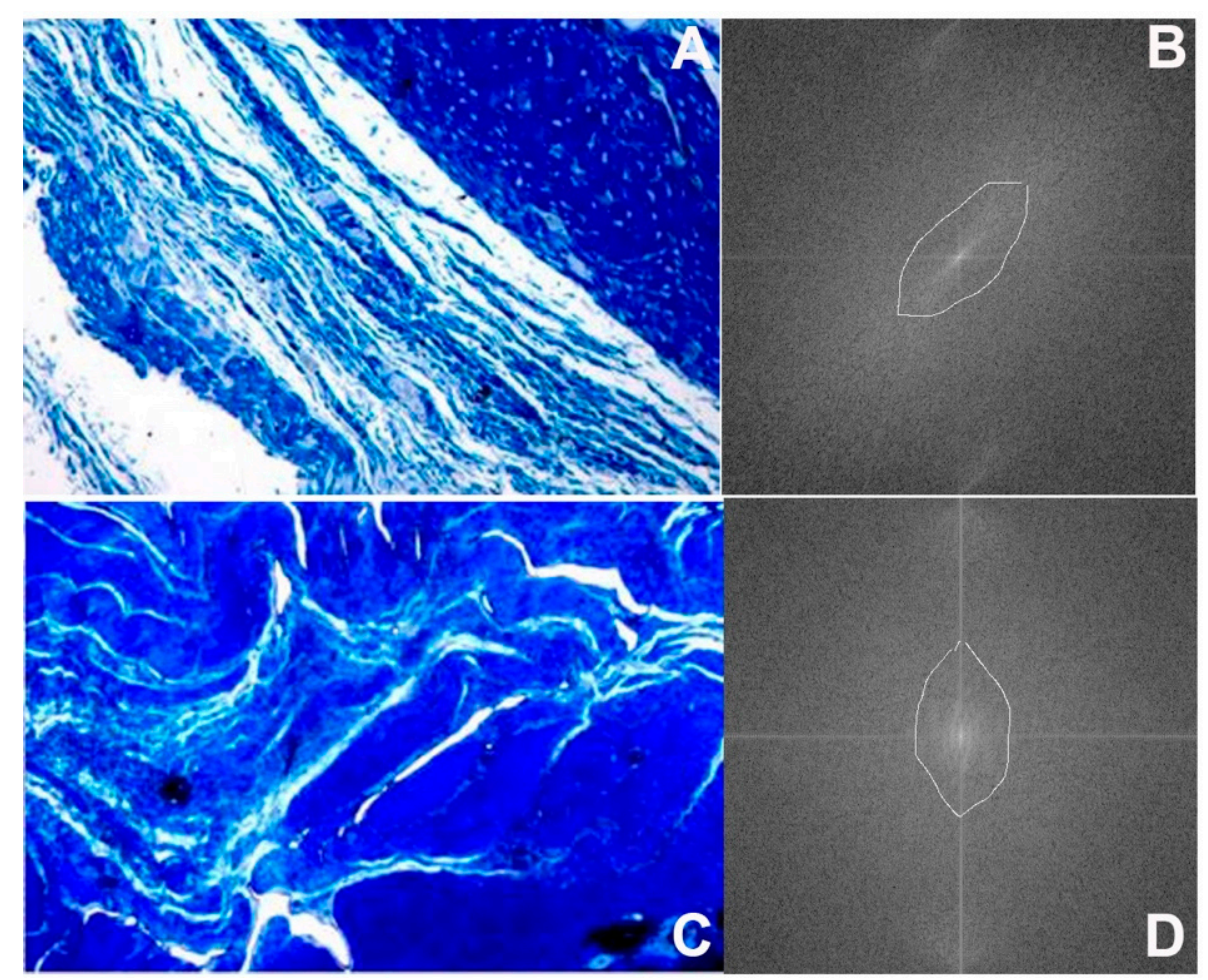

Figure 5. Measurement of collagen bundle orientation by Fourier analysis. Histological microphotographs were processed with a best fit filter $(\mathbf{A}, \mathbf{C})$. The fast Fourier transform was obtained, and the maximum length and width of the central structure was automatically calculated to obtain the collagen orientation index of the picture (B,D), with a collagen orientation index of 0.88 for the non-treated group (D) and a collagen orientation index of 0.5 for the Hyaloglide group (B).

\subsection{Gene Expression}

A detailed analysis of the gene expression of the extracellular matrix components involved in tenogenesis is reported in Figure 7. Significant alteration of sclerodermin (SCX), tenascin (TNC), and collagen type I (Coll 1 a 1 ) expression, $n$ related to good tissue regeneration, on treated tendons is observed. On the contrary, a defined reduction of collagen type III, closed to a scar tissue, is observed.

Nowadays, miRNAs represent an important tool in biological and medical fields, due to their crucial role as biomarkers of regeneration. At the post-transcriptional level, miRNAs are known to influence both the stability and protein expression of their mRNA targets. For this reason, these are now considered key regulators of several biological processes, including tissue regeneration. In the light of such considerations, in the last part of this work, we evaluated the expression of the most mature miRNAs known as negative inducers of tenogenesis. As reported in Figure 7, all the miRNAs related to the positive effects of tendon regeneration were found to be upregulated in the treated tendon. On the contrary, miR-29b-3p, which is a negative regulator of tenogenesis, was found to be downregulated in the treated group. 

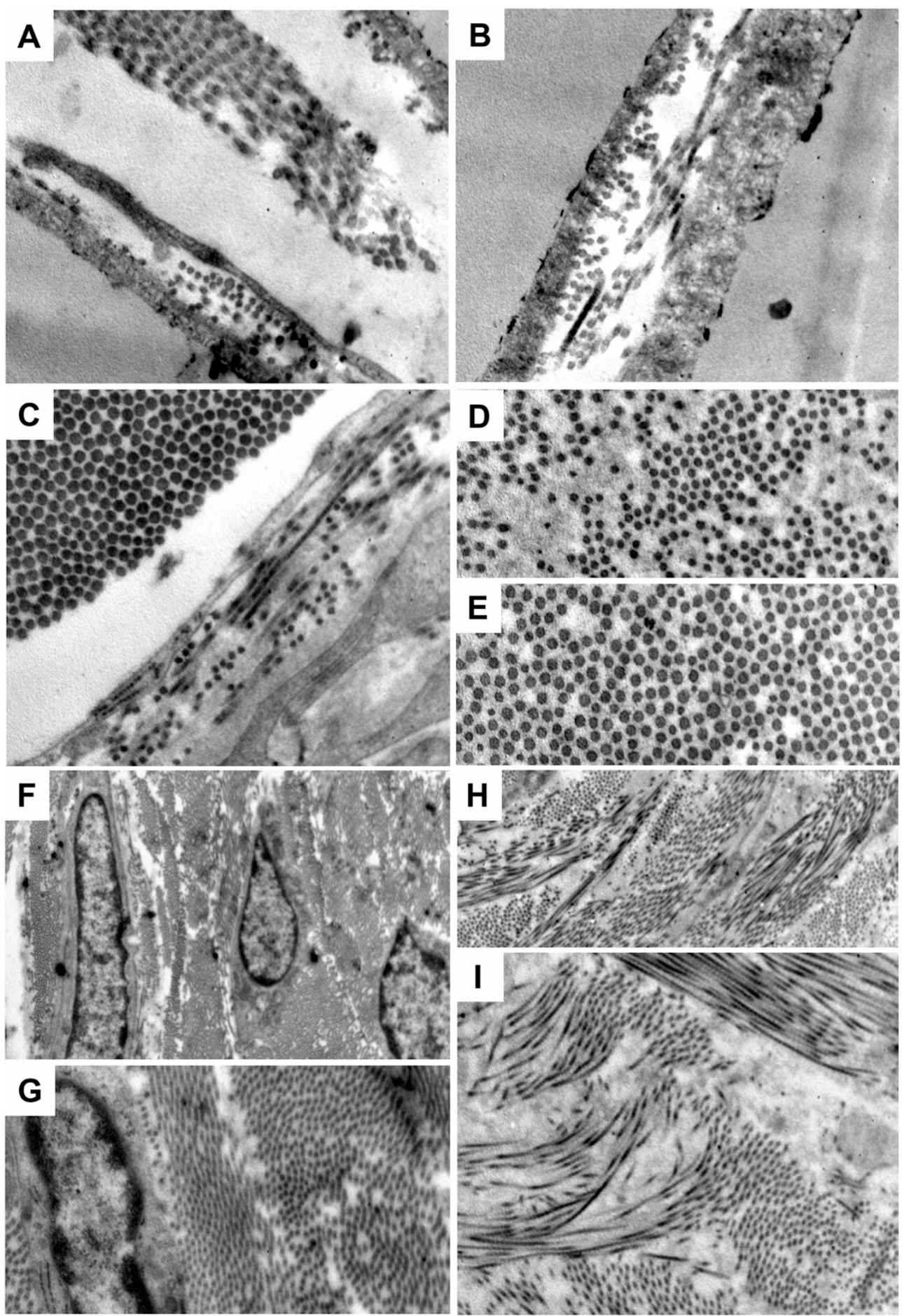

Figure 6. Electron microscopy analysis. (A) Normal undamaged tendon. (B-E) Hyaloglide ${ }^{\circledR}$ group. $(\mathbf{F}-\mathbf{H})$ Control untreated group. Magnification: $(\mathbf{A}, \mathbf{B})=50,000 X ;(C-E)=60,000 X ;(F)=10,000 X$; $(\mathbf{G})=30,000 X ;(\mathbf{H})=15,000 X ;(\mathbf{I})=25,000 X$.

\subsection{Biomechanical Evaluations}

As regards the failure load, no significant differences $(p=0.75)$ were observed between the control group (median $79.68 \mathrm{~N}$ range 49.45-105.89) and the group with tendons treated with Hyaloglide ${ }^{\circledR}$ (median $74.87 \mathrm{~N}$ median 44.87-104.40). 


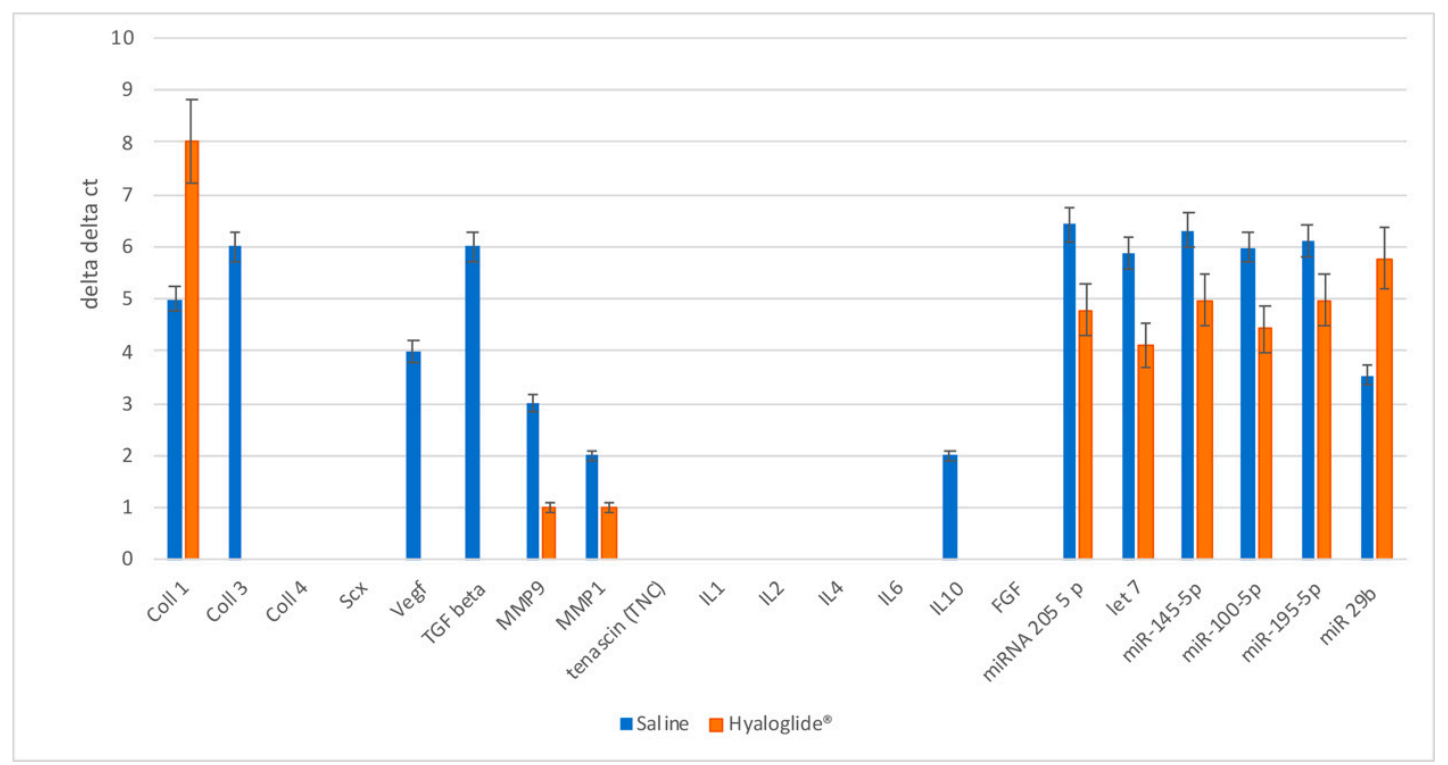

Figure 7. Real-time PCR analysis of proteins related to growth factors, miRNA, and enzymes involved in tendon regeneration and repair. The results for each experiment were obtained from triplicate experiments and values are expressed as the mean \pm SD.

\section{Discussion}

Tenolysis is a common inflammatory response resulting in scar tissue formation and inhibits synovial sheath regeneration, which will subsequently impede the gliding function of the tendon and restrict related movements, e.g., digital flexion [42]. Over the last 25 years, researchers have been striving to overcome this clinical challenge, with positive advances in wound healing research regarding the molecules and cells related to the healing process. Hence, characterization of the growth factors involved in tendon wound healing is paving the way towards a new era of potential anti-adhesion treatments. Numerous studies have evaluated the efficacy of HA on adhesions, gliding resistance, and tendon healing [42-44]. Different in vitro models have been used, including animals (dog, chicken, rabbit, rat, and horse) [21-23,45], tendons [46,47], and procedures of induced tendon damage (surgical, collagenase, or steroid lesion). So far, numerous studies have evaluated in vitro responses in animal models regarding the effect of various growth factors or the impact of the same growth factor inhibitors to monitor the healing process and acquire adhesion-free tendons [48-52]. Nevertheless, a limited number of pre-clinical studies have led to clinical trials, and to date, no favorable clinical outcomes have been obtained regarding adhesion reduction, although some adhesion barriers have demonstrated satisfactory clinical efficacy.

An absorbable autocross-linked hyaluronan-based gel (Hyaloglide ${ }^{\circledR}$ ) [3] is an adhesion barrier. Herein, we reported the efficacy of Hyaloglide ${ }^{\circledR}$ application post tenolysis in a rabbit model to prevent post-surgical peritendinous adhesions. The data herein contributes to and extends existing knowledge concerning the restoration of neighbouring tendons (synovial tendon sheaths). Noteworthy is the avoidance of adherence, which induces improved synovial regeneration as illustrated in the ultrastructural analysis. Our findings suggest that Hyaloglide ${ }^{\circledR}$ application prevents peritendinous adhesions after tenolysis. This process is attributable to the facilitating role of the treatment in reorganizing the tendon sheaths. Hyaloglide ${ }^{\circledR}$ and specifically the sodium hyaluronate component of the gel [20] compensate for the loss of synovial fluid [53] commonly occurring after tenolysis and is imperative for the restoration of peritendinous sheaths.

Hyaloglide ${ }^{\circledR}$ was not observed upon macroscopic examination during the explants nor was it observed upon microscopic examination after histological staining with H\&E and Masson's trichrome staining. Numerous quantitative and qualitative procedures have been used in histological investigations. Adhesions were classified into four grades by Tang [36] as follows: no adhesions, few adhesions, moderate adhesions, and severe adhesions. This 
grading considered the presence of adhesions, the extending length of adhesions, and the density of filamentous fibers. Weeks and Wray [54] classified adhesions into two different groups: (i) loose adhesions, which may be released by physical activity to improve the tendon glide, and (ii) dense adhesions, which are generally difficult to release. Furthermore, the authors noted that the adhesive tissues resulting from the subcutaneous tissue and the fat would become loose adhesions and adhesive tissues from the palmar fascia, volar plate, tendon sheath, and periosteum would become dense adhesions. Biochemical examination of adhesion tissue specimens was conducted in each group. It is well known that upon inflammatory trigger/stimuli, such as in the presence of adhesion tissue related to scar formation, tenocytes tend to express inflammatory cytokines, including tumor necrosis factor (TNF)- $\alpha$; interleukin (IL)-1 $\beta$, IL-6, and IL-21; and transforming growth factor (TGF)$\beta$. Of note, tendon tissues in the presence of bad healing do not show the classical histology of inflammation but an alteration of collagen type II fibers. So far, the epigenetics associated with tendon disorders could represent a novel tool. Moreover, several miRNAs have been reported to be involved in tendon disorders and inflammation [55-57]. These studies revealed the alteration of hundreds of miRNAs, which are considered to be associated with the pathological changes in the tendon. Among them, miR-145-5p, miR-100-5p, miR-195-5p, and let-7 were found to be the key miRNAs and warrant further detailed investigations. With this in mind, on our tested sample, their alteration confirms that in the untreated tendon, their expression is negatively correlated with tenogenesis, which is higher compared to the one related to the treated tendons.

\section{Conclusions}

The findings observed within the present study strongly support the efficacy of local Hyaloglide ${ }^{\circledR}$ application around the tendon as a favorable alternative to prevent adhesions after tendon surgery, a finding that was further confirmed by a clinical randomized multicenter trial. This treatment may be particularly indicated in cases of extensive injury to the tendon sheath and the presence of tenolysis. The absorbable anti-adhesion action of the gel plays a fundamental role in the repair of the peritendinous synovial sheaths. In addition, the potential of the hyaluronate autocross-linked gel may support the growth factors or cells to enhance the biological tendon healing process.

Author Contributions: Conceptualization, A.M. and M.R.; methodology, A.M.; validation, F.D.F.; formal analysis, A.M., A.C., P.P.P., B.Z., S.G.; investigation, A.M., A.C., P.P.P., B.Z., S.G.; resources, V.R., M.R.; data curation, F.D.F.; writing-original draft preparation, A.M.; writing-review and editing, F.D.F., L.S.; supervision, F.D.F., M.R.; project administration, M.R. All authors have read and agreed to the published version of the manuscript. Please turn to the CRediT taxonomy for the term explanation. Authorship must be limited to those who have contributed substantially to the work reported.

Funding: This research received no external funding.

Institutional Review Board Statement: All institutional and national guidelines for the care and use of laboratory animals were followed and all procedures were performed with the approval of the local Institution's Animal Care and Ethics Committee and in accordance with the European Communities Council Directive of 22 September 2010 (2010/63/UE).

Informed Consent Statement: Not applicable.

Data Availability Statement: The datasets generated during and/or analyzed during the current study are available from the corresponding author upon reasonable request.

Conflicts of Interest: The authors declare that they have no conflict of interest. 


\section{References}

1. Kannus, P. Structure of the tendon connective tissue. Scand. J. Med. Sci. Sports 2000, 10, 312-320. [CrossRef]

2. Boyer, M.I. Flexor Tendon Biology. Hand Clin. 2005, 21, 159-166. [CrossRef]

3. Riccio, M.; Battiston, B.; Pajardi, G.; Corradi, M.; Passaretti, U.; Atzei, A.; Altissimi, M.; Vaienti, L.; Catalano, F.; Del Bene, M.; et al. Study Group on Tendon Adhesion of Italian Society of Hand Surgery. Efficiency of Hyaloglide in the prevention of the recurrence of adhesions after tenolysis of flexor tendons in zone II: A randomized, controlled, multicentre clinical trial. J. Hand Surg. Eur. 2010, 35, 130-138. [CrossRef]

4. Branford, O.A.; Lee, D.A.; Bader, D.L.; Grobbelaar, A.O. The mechanics of flexor tendon adhesions. J. Hand Surg. Eur. 2012, 37, 555-563. [CrossRef]

5. Chang, J. Studies in Flexor Tendon Reconstruction: Biomolecular Modulation of Tendon Repair and Tissue Engineering. J. Hand Surg. Am. 2012, 37, 552-561. [CrossRef] [PubMed]

6. Mass, D.P.; Tuel, R.J. Intrinsic healing of the laceration site in human superficialis flexor tendons in vitro. J. Hand Surg. 1991, 16, 24-30. [CrossRef]

7. Boyer, M.I.; Goldfarb, C.A.; Gelberman, R.H. Recent Progress in Flexor Tendon Healing. J. Hand Ther. 2005, 18, 80-85. [CrossRef] [PubMed]

8. Strickland, J.W. The Scientific Basis for Advances in Flexor Tendon Surgery. J. Hand Ther. 2005, 18, 94-110. [CrossRef]

9. Strauch, B.; de Moura, W.; Ferder, M.; Hall, C.; Sagi, A.; Greenstein, B. The fate of tendon healing after restoration of the integrity of tendon sheath with autogenous vein grafts. J. Hand Surg. Am. 1985, 10, 790-795. [CrossRef]

10. Dogramaci, Y.; Duman, I.G. Reinforcement of the Flexor Tendon Repair Using Human Amniotic Membrane: A Biomechanical Evaluation Using the Modified Kessler Method of Tendon Repair. J. Am. Podiatr. Med. Assoc. 2016, 106, 319-322. [CrossRef]

11. Oei, T.S.; Klopper, P.J.; Spaas, J.A.; Buma, P. Reconstruction of the flexor tendon sheath. An experimental study in rabbits. J. Hand Surg. Br. 1996, 21, 72-83. [CrossRef]

12. Sungur, N.; Uysal, A.I.; Kocer, U.U.; Karaaslan, O.; Gumus, M.; Sokmensuer, L.K.; Sokmensuer, C. Prevention of Tendon Adhesions by the Reconstruction of the Tendon Sheath With Solvent Dehydrated Bovine Pericard: An Experimental Study. J. Trauma 2006, 61, 1467-1472. [CrossRef]

13. Tham, S.K.; Ireland, D.C.; Riccio, M.; Morrison, W.A. Reverse radial artery fascial flap: A treatment for the chronically scarred median nerve in recurrent carpal tunnel syndrome. J. Hand Surg. Am. 1996, 21, 849-854. [CrossRef]

14. Riccio, M.; Bertani, A.; Morrison, W.A. Reverse Island Forearm Flaps for the Coverage 46 of the Median Nerve in Recurrent Carpal Tunnel Syndrome. In Carpal Tunnel Syndrome; Luchetti, R., Amadio, P., Eds.; Springer: Berlin, Germany, 2006; pp. 343-359.

15. Frykman, E.; Jacobsson, S.; Widenfalk, B. Fibrin sealant in prevention of flexor tendon adhesions: An experimental study in the rabbit. J. Hand Surg. Am. 1993, 18, 68-75. [CrossRef]

16. He, M.; Gan, A.W.T.; Lim, A.Y.T.; Goh, J.C.H.; Hui, J.H.P.; Lee, E.H.; Chong, A.K.S. The effect of fibrin glue on tendon healing and adhesion formation in a rabbit model of flexor tendon injury and repair. J. Plast. Surg. Hand Surg. 2013, 47, 509-512. [PubMed]

17. Siddiqi, N.A.; Hamada, Y.; Ide, T.; Akamatsu, N. Effects of hydroxyapatite and alumina sheaths on postoperative peritendinous adhesions in chickens. J. Appl. Biomater. 1995, 6, 43-53. [CrossRef]

18. Hanff, G.; Hagberg, L. Prevention of restrictive adhesions with expanded polytetrafluoroethylene diffusible membrane following flexor tendon repair: An experimental study in rabbits. J. Hand Surg. Am. 1998, 23, 658-664. [CrossRef]

19. Thomas, S.C.; Jones, L.C.; Hungerford, D.S. Hyaluronic acid and its effect on postoperative adhesions in the rabbit flexor tendon. A preliminary look. Clin. Orthop. Relat. Res. 1986, 206, 281-289.

20. Hagberg, L.; Gerdin, B. Sodium hyaluronate as an adjunct in adhesion prevention after flexor tendon surgery in rabbits. J. Hand Surg. Am. 1992, 17, 935-941. [CrossRef]

21. Işik, S.; Oztürk, S.; Gürses, S.; Yetmez, M.; Guler, M.M.; Selmanpakoglu, N.; Gunhan, O. Prevention of restrictive adhesions in primary tendon repair by HA-membrane: Experimental research in chickens. Br. J. Plast. Surg. 1999, 52, 373-379. [CrossRef]

22. Moro-oka, T.; Miura, H.; Mawatari, T.; Kawano, T.; Nakanishi, Y.; Higaki, H.; Iwamoto, Y. Mixture of hyaluronic acid and phospholipid prevents adhesion formation on the injured flexor tendon in rabbits. J. Orthop. Res. 2000, 18, 835-840. [CrossRef]

23. Nishida, J.; Araki, S.; Akasaka, T.; Toba, T.; Shimamura, T.; Amadio, P.C.; An, K.N. Effect of hyaluronic acid on the excursion resistance of tendon grafts. A biomechanical study in a canine model in vitro. J. Bone Jt. Surg. Br. 2004, 86, 918-924. [CrossRef]

24. Akasaka, T.; Nishida, J.; Imaeda, T.; Shimamura, T.; Amadio, P.C.; An, K.N. Effect of hyaluronic acid on the excursion resistance of tendon graft: A biomechanical in vitro study in a modified human model. Clin. Biomech. 2006, 21, 810-815. [CrossRef] [PubMed]

25. Dahl, L.; Hopwood, J.J.; Laurent, U.B.; Lilja, K.; Tengblad, A. The concentration of hyaluronate in amniotic fluid. Biochem. Med. 1983, 30, 280-283. [CrossRef]

26. Ozgenel, G.Y. The effects of a combination of hyaluronic and amniotic membrane on the formation of peritendinous adhesions after flexor tendon surgery in chickens. J. Bone Jt. Surg. Br. 2004, 86, 301-307. [CrossRef]

27. De Iaco, P.A.; Stefanetti, M.; Pressato, D.; Piana, S.; Donà, M.; Pavesio, A.; Bovicelli, L. A novel hyaluronan-based gel in laparoscopic adhesion prevention: Preclinical evaluation in an animal model. Fertil. Steril. 1988, 69, 318-323.

28. Belluco, C.; Meggiolaro, F.; Pressato, D.; Pavesio, A.; Bigon, E.; Donà, M.; Forlin, M.; Nitti, D.; Lise, M. Prevention of postsurgical adhesions with an autocrosslinked hyaluronan derivative gel. J. Surg. Res. 2001, 100, 217-221. [CrossRef] [PubMed]

29. Brunelli, G.; Longinotti, C.; Bertazzo, C.; Pavesio, A.; Pressato, D. Adhesion reduction after knee surgery in a rabbit model by Hyaloglide, a hyaluronan derivative gel. J. Orthop. Res. 2005, 23, 1377-1382. 
30. Atzei, A.; Calcagni, M.; Breda, B.; Fasolo, G.; Pajardi, G.; Cugola, L. Clinical evaluation of a hyaluronan-based gel following microsurgical reconstruction of peripheral nerves of the hand. Microsurgery 2007, 27, 2-7. [CrossRef]

31. Riccio, M.; Marchesini, A.; Senesi, L.; Skrami, E.; Gesuita, R.; De Francesco, F. Managing pathologic scars by injecting auto-crosslinked Hyaluronic Acid: A preliminary prospective clinical study. Aesthetic Plast. Surg. 2019, 43, 480-489. [CrossRef]

32. Imere, A.; Ligorio, C.; O’Brien, M.; Wong, J.K.F.; Domingos, M.; Cartmell, S.H. Engineering a cell-hydrogel-fibre composite to mimic the structure and function of the tendon synovial sheath. Acta Biomater. 2021, 119, 140-154. [CrossRef]

33. Chen, C.T.; Chen, C.H.; Sheu, C.; Chen, J.P. Ibuprofen-Loaded Hyaluronic Acid Nanofibrous Membranes for Prevention of Postoperative Tendon Adhesion through Reduction of Inflammation. Int. J. Mol. Sci. 2019, 20, 5038. [CrossRef]

34. Yurdakul Sıkar, E.; Sıkar, H.E.; Top, H.; Aygit, A.C. Effects of Hyalobarrier gel and Seprafilm in preventing peritendinous adhesions following crush-type injury in a rat model. Turk. J. Trauma Emerg. Surg. 2019, 25, 93-98. [CrossRef]

35. Carpenter, J.E.; Thomopoulos, S.; Soslowsky, L.J. Animal models of tendon and ligament injuries for tissue engineering applications. Clin. Orthop. Relat. Res. 1999, 367, S296-S311. [CrossRef]

36. Tang, J.B. Clinical outcomes associated with flexor tendon repair. Hand Clin. 2005, 21, 199-210. [CrossRef] [PubMed]

37. Soslowsky, L.J.; Carpenter, J.E.; DeBano, C.M.; Banerji, I.; Moalli, M.R. Development and use of an animal model for investigations on rotator cuff disease. J. Shoulder Elbow Surg. 1996, 5, 383-392. [CrossRef]

38. Cook, J.L.; Feller, J.A.; Bonar, S.F.; Khan, K.M. Abnormal tenocyte morphology is more prevalent than collagen disruption in asymptomatic athletes' patellar tendons. J. Orthop. Res. 2004, 2, 334-338. [CrossRef]

39. Svensson, M.; Kartus, J.; Christensen, L.R.; Movin, T.; Papadogiannakis, N.; Karlsson, J. A long-term serial histological evaluation of the patellar tendon in humans after harvesting its central third. Knee Surg. Sports Traumatol. Arthrosc. 2005, 13, 398-404. [CrossRef]

40. van Zuijlen, P.P.; de Vries, H.J.; Lamme, E.N.; Coppens, J.E.; van Marle, J.; Kreis, R.W.; Middelkoop, E. Morphometry of dermal collagen orientation by Fourier analysis is superior to multi-observer assessment. J. Pathol. 2002, 198, 284-291. [CrossRef] [PubMed]

41. Oliva, F.; Maffulli, N.; Gissi, C.; Veronesi, F.; Calciano, L.; Fini, M.; Brogini, S.; Gallorini, M.; Antonetti Lamorgese Passeri, C.; Bernardini, R.; et al. Combined ascorbic acid and $\mathrm{T}_{3}$ produce better healing compared to bone marrow mesenchymal stem cells in an Achilles tendon injury rat model: A proof of concept study. J. Orthop. Surg. Res. 2019, 14, 54. [CrossRef]

42. Abate, M.; Schiavone, C.; Salini, V. The use of hyaluronic acid after tendon surgery and tendinopathies. BioMed Res. Int. 2014, 2014, 783632. [CrossRef] [PubMed]

43. Amiel, D.; Ishizue, K.; Billings Jr, E.; Wiig, M.; Vande Berge, J.; Akeson, W.H.; Gelberman, R. Hyaluronan in flexor tendon repair. J. Hand Surg. 1989, 14, 837-843. [CrossRef]

44. Gervasi, M.; Barbieri, E.; Capparucci, I.; Annibalini, G.; Sisti, D.; Amatori, S.; Carrabs, V.; Valli, G.; Donati Zeppa, S.; Rocchi, M.B.L.; et al. Treatment of Achilles tendinopathy in recreational runners with peritendinous hyaluronic acid injections: A viscoelastometric, functional, and biochemical pilot study. J. Clin. Med. 2021, 10, 1397. [CrossRef] [PubMed]

45. Ahn, K.H.; Ahn, K.H.; Park, E.S.; Choi, C.Y.; Cha, H.G.; Hwang, Y.; Nam, S.M. Hyaluronic Acid Treatment Improves Healing of the Tenorrhaphy Site by Suppressing Adhesions through Extracellular Matrix Remodeling in a Rat Model. Polymers 2021, 13, 928. [CrossRef] [PubMed]

46. Wiig, M.; Abrahasmsson, S.O. Hyaluronic acid modulates cell proliferation unequally in intrasynovial and extrasynovial rabbit tendons in vitro. J. Hand Surg. Br. 2000, 25, 183-187. [CrossRef] [PubMed]

47. Farnebo, S.; Wiig, M.; Holm, B.; Ghafouri, B. Differentially expressed proteins in intra synovial compared to extra synovial flexor tendon grafts in a rabbit tendon transplantation model. Biomedicines 2020, 8, 10. [CrossRef]

48. Kakar, S.; Khan, U.; McGrouther, D.A. Differential cellular response within the rabbit tendon unit following tendon injury. J. Hand Surg. Br. 1998, 23, 627-632. [CrossRef]

49. Wu, Y.F.; Mao, W.F.; Zhou, Y.L.; Wang, X.T.; Liu, P.Y.; Tang, J.B. Adeno-associated virus-2-mediated TGF- $\beta 1$ microRNA transfection inhibits adhesion formation after digital flexor tendon injury. Gene Ther. 2015, 23, 167-175. [CrossRef]

50. Shen, H.; Kormpakis, I.; Havlioglu, N.; Linderman, S.W.; Sakiyama-Elbert, S.E.; Erickson, I.E.; Zarembinski, T.; Silva, M.J.; Gelberman, R.H.; Thomopoulos, S. The effect of mesenchymal stromal cell sheets on the inflammatory stage of flexor tendon healing. Stem Cell Res. Ther. 2016, 7, 144. [CrossRef]

51. Linderman, S.W.; Shen, H.; Yoneda, S.; Jayaram, R.; Tanes, M.L.; Sakiyama-Elbert, S.; Xia, Y.; Thomopoulos, S.; Gelberman, R.H. Effect of connective tissue growth factor delivered via porous sutures on the proliferative stage of intrasynovial tendon repair. J. Orthop. Res. 2018, 36, 2052-2063. [CrossRef]

52. Zhou, Y.; Yang, Q.; Yan, Y.; Zhu, C.; Zhang, L.; Tang, J.B. Localized Delivery of miRNAs Targets Cyclooxygenases and Reduces Flexor Tendon Adhesions. Acta Biomater. 2018, 70, 237-248. [CrossRef]

53. Wiig, M.; Abrahamsson, S.O.; Lundborg, G. Effects of hyaluronan on cell proliferation and collagen synthesis: A study of rabbit flexor tendons in vitro. J. Hand Surg. Am. 1996, 21, 599-604. [CrossRef]

54. Wray, R.C., Jr.; Gagnes, R.; Lowry, R.; Weeks, P.M. Effect of stress on the mechanical properties of tendon adhesions. Surg. Forum 1974, 25, 520-521. [PubMed]

55. Lu, Y.F.; Liu, Y.; Fu, W.M.; Xu, J.; Wang, B.; Sun, Y.X.; Wu, T.Y.; Xu, L.L.; Chan, K.M.; Zhang, J.F.; et al. Long noncoding RNA H19 accelerates tenogenic differentiation and promotes tendon healing through targeting miR-29b-3p and activating TGF-beta1 signaling. FASEB J. 2017, 31, 954-964. [CrossRef] [PubMed] 
56. Thankam, F.G.; Boosani, C.S.; Dilisio, M.F.; Agrawal, D.K. Epigenetic mechanisms and implications in tendon inflammation. Int. J. Mol. Med. 2019, 43, 3-14. [CrossRef] [PubMed]

57. Xu, Q.; Sun, W.X.; Zhang, Z.F. High expression of VEGFA in MSCs promotes tendon-b one healing of rotator cuff tear via microRNA-205-5p. Eur. Rev. Med. Pharmacol. Sci. 2019, 23, 4081-4088. 